\title{
Jacqueline Lalouette, Xavier Boniface, Jean-François Chanet et Imelda Elliot (dir.) Les religions à l'école. Europe et Amérique du Nord XIXe-XXIe siècles
}

Paris : Letouzey et Ané, 2011, 344 pages

\section{Jean-Marc Charron}

Université de Montréal

Cet ouvrage est constitué des Actes du colloque Dieu à l'école. Éducation et religion en Europe du Nord-Ouest et en Amérique du Nord de 1800 à nos jours, tenu à l'Université du Littoral-Côte d'Opale en décembre 2007. Il rassemble vingt-et-une interventions regroupées sous quatre grands thèmes : 1 . De la prééminence catholique au pluralisme religieux; 2. De l'enseignement de la religion à celui du fait religieux; 3 . L'idéologie en cause; 4. Processus de laïcisation et de sécularisation.

Le thème choisi, pour ce colloque, était vaste tant il en couvrait large sur les plans géographique, historique et chronologique. Le risque était grand de se retrouver avec un ensemble de contributions, chacune en soi intéressante, mais sans lien ni fil conducteur. Heureusement, les organisateurs et les éditeurs des actes de ce colloque ont su donner une cohérence d'ensemble à cette réflexion en ordonnant les diverses interventions sous les quatre grands thèmes mentionnés. Malgré le fait que la majorité des intervenants et intervenantes soit d'origine française ou ouvre dans des institutions de l'Hexagone, la teneur des articles réussit très bien à nous brosser un tableau d'ensemble de l'évolution et de la réalité actuelle de la prise en compte du religieux dans l'institution scolaire tant en Europe que sur une partie du continent nord-américain.

La place dévolue à la réalité religieuse en éducation est intimement liée au contexte historique, politique et juridique de chaque société. Elle traduit, à sa manière, l'histoire des rapports entre religion et politique, religion et culture. $\mathrm{Si}$, au fil du temps, ces différentes sociétés ont su trouver un équilibre, dans la gestion du religieux, correspondant à leur situation particulière, largement marquée par la forte présence du 
christianisme dans la majorité des sociétés occidentales, elles sont toutes confrontées aujourd'hui à une redéfinition de leurs modes de gestion sur la base de la sécularisation, de la recomposition des croyances et du pluralisme religieux et convictionnel. L'école, comme institution de normalisation sociale, est alors conviée à une révision de ses façons de faire eu égard à l'éducation religieuse. Jean-Paul Willaime illustre très bien cet état de fait dans sa contribution qui tient lieu de conclusion à ce volume et intitulée $Y$ a-t-il une européanisation de l'enseignement relatifà la religion? Ce qu'il met en évidence quant aux différents modèles de prise en compte du religieux en éducation dans le contexte européen marqués par les diverses situations nationales (enseignement religieux confessionnel, enseignement non confessionnel des religions, absence d'un enseignement spécifique des religions), peut tout aussi bien s'appliquer à la réalité nord-américaine en général qu'à l'évolution récente du Québec en particulier, comme l'illustrent si bien les textes de Mireille Estivalèzes (L'enseignement sur les religions à l'école à l'épreuve du pluralisme culturel en France et au Québec) et d'Arnaud Decroix (Le système éducatif canadien face aux revendications de nature religieuse : quelques considérations de nature juridique).

L'ensemble des contributions fait très bien ressortir le fait que la gestion du religieux en éducation demeure fortement marquée par le l'histoire religieuse des pays concernés et la position majoritaire d'une tradition religieuse particulière. Patricia Fournier Noël (Immigration et remise en question de la place de Dieu à l'école : étude de cas d'écoles primaire en Irlande) illustre bien combien la puissance de l'Église catholique en Irlande influe sur la prise en compte de la diversité religieuse. Situation qui n'est pas étrangère aux débats que nous avons connus au Québec et qui ont précédé la déconfessionnalisation du système scolaire et la mise en place d'un programme d'enseignement des religions en phase avec la réalité socioreligieuse et les défis du pluralisme. Dans le même sens, les contributions de Mokhtar Ben Barka (La controverse relative à l'enseignement du créationnisme aux États-Unis) et de Carole MasseysBertonèche (Religion et enseignement supérieur américain : une lä̈cisation inachevée) font ressortir la prégnance des traditions protestantes évangéliques dans la culture américaine et les rapports complexes du politique et du religieux malgré le « mur de séparation " inscrit dans la constitution américaine.

Si trop souvent, dans les débats entourant la place de la religion dans les institutions publiques, plusieurs ont tendance à croire que la "laïcité à la française » serait le modèle dominant — discours qui n'est pas étranger à nos débats québécois - cet ouvrage illustre bien que la réalité est plus complexe et, surtout, plus diversifiée. Pour ceux et celles qui s'intéressent de près à la place de la religion à l'école, tout autant qu'à l'histoire religieuse et à l'évolution des équilibres entre le politique et le religieux, ce volume constitue une référence stimulante permettant une mise en perspective de nos débats nationaux respectifs. 